
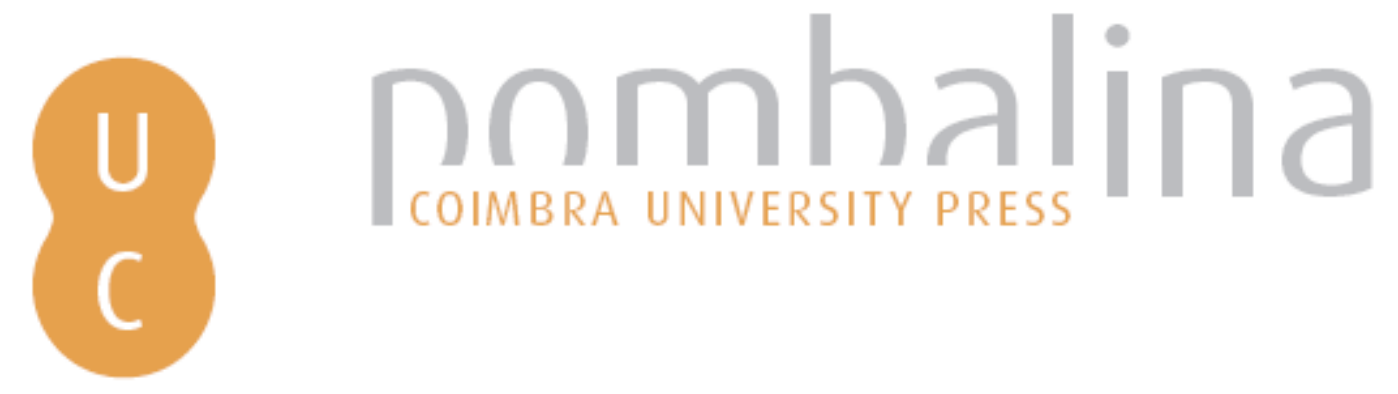

\title{
A felicidade perdida: animais que falam e a ontologia da cidade platônica
}

\author{
Autor(es): $\quad$ Cornelli, Gabriele
}

Publicado por: Imprensa da Universidade de Coimbra

URL

persistente: URI:http://hdl.handle.net/10316.2/45158

DOI: $\quad$ DOI:https://doi.org/10.14195/978-989-26-1679-7_17

Accessed : $\quad$ 26-Apr-2023 11:20:18

A navegação consulta e descarregamento dos títulos inseridos nas Bibliotecas Digitais UC Digitalis, UC Pombalina e UC Impactum, pressupõem a aceitação plena e sem reservas dos Termos e Condições de Uso destas Bibliotecas Digitais, disponíveis em https://digitalis.uc.pt/pt-pt/termos.

Conforme exposto nos referidos Termos e Condições de Uso, o descarregamento de títulos de acesso restrito requer uma licença válida de autorização devendo o utilizador aceder ao(s) documento(s) a partir de um endereço de IP da instituição detentora da supramencionada licença.

Ao utilizador é apenas permitido o descarregamento para uso pessoal, pelo que o emprego do(s) título(s) descarregado(s) para outro fim, designadamente comercial, carece de autorização do respetivo autor ou editor da obra.

Na medida em que todas as obras da UC Digitalis se encontram protegidas pelo Código do Direito de Autor e Direitos Conexos e demais legislação aplicável, toda a cópia, parcial ou total, deste documento, nos casos em que é legalmente admitida, deverá conter ou fazer-se acompanhar por este aviso.

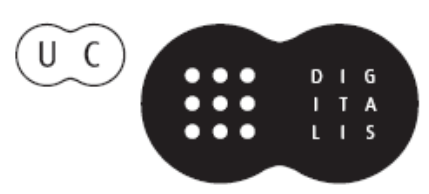



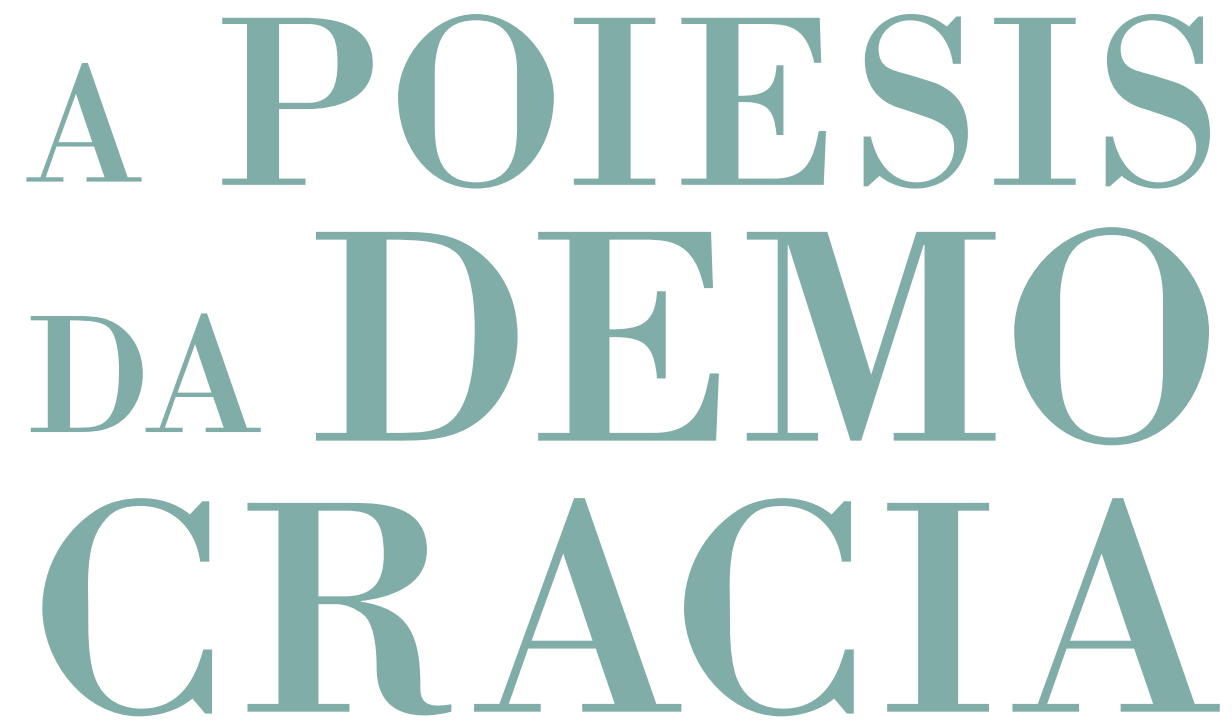

G

Breno Battistin Sebastiani, Delfim Leão,

Lugia Sano, Martinho Soares, Christian Werner

\section{CoimbraCompanions}




\title{
A felicidade perdida:
}

ANIMAIS QUE FALAM E A ONTOLOGIA DA

CIDADE PLATÔNICA

\author{
THE LOST HAPPINESS: \\ TALKING ANIMALS AND THE ONTOLOGY OF \\ THE PLATONIC CITY
}

Gabriele Cornelli

UNIVERSIDADE DE BRASÍLIA

ORCID | 0000-0002-5588-7898 


\section{Resumo}

A proposta do presente ensaio - que definiria agambeniano por inspiração e método - é aquela de compreender de que maneira uma metafísica da conjunção/separação entre corpo e alma permite a Platão a definição de um espaço político para o ser humano pensado em relação àquele do animal. O ensaio partirá da página $P h d$. 60c-61c e à menção inédita de um Sócrates que põe em música as fábulas de Esopo e irá até a página Pol. 272b-c, onde encontrará novamente as palavras dos animais. Essas palavras, nas páginas platônicas, são sempre atemporais, no sentido que se põem fora do curso normal do tempo. Estão fora para poder ser deste mesmo curso a norma de referência. Trata-se de um estado de bem-aventurança originária, pré-política, mas que é pensada como indicação de uma felicidade latente, de uma norma de convivência política a ser recuperada no tempo presente. Com consequências teóricas e práticas importantes para o esforço platônico de compreender tanto a crise da democracia, que matou Sócrates, como a própria definição da melhor forma de governo para Atenas.

\section{Palavras-chave}

Platão, animais, polis, democracia 


\section{Abstract}

The purpose of this paper - which I would consider Agambenian by inspiration and method - is to understand how the metaphysics of the conjunction / separation between body and soul allows Plato to define a political space for the human being in relation to that of the animal. The paper will start on page $P h d$. 60c-61c with the unprecedented mention of Socrates putting Aesop's fables to music, and will end on page Pol. 272b-c, where he will find the words of animals once again. These words, in the Plato's writings, are always timeless, i.e. they stand outside the normal course of time. Their being outside allows them to act as the norm of reference for this same course. It is a sort of pre-political bliss, but it is thought of as an indication of a latent happiness, of a norm of political coexistence that ought to be recovered in the present time. This research has important theoretical and practical consequences for the Platonic effort to understand both the crisis of democracy that killed Socrates, and the very definition of the best form of government for Athens.

\section{Keywords}

Plato, animals, polis, democracy 


\section{INTRODUÇÃO}

Numa recente releitura de O Aberto de Giorgio Agamben chamou-me atenção uma página programática do Autor, que é hoje um dos mais estudados filósofos políticos contemporâneos:

Nella nostra cultura, l'uomo è sempre stato pensato come l'articolazione e la congiunzione di un corpo e di un'anima, de un vivente e di un logos, di un elemento naturale (o animale) e di un elemento soprannaturale, sociale o divino. Dobbiamo invece imparare a pensare l'uomo come ciò che risulta dalla sconnessione di questi due elementi e investigare non il mistero metafisico della congiunzione, ma quello pratico e politico della separazione. Che cos'è l'uomo se esso è sempre il luogo - e insieme il risultato - di divisioni e cesure incessanti? Lavorare su queste divisioni, chiedersi in che modo - nell'uomo - l'uomo è stato separato dal non-uomo e l'animale dall'umano, è più urgente che prendere posizione sulle grandi questioni, su cosiddetti valori e diritti umani. ${ }^{1}$

Trabalhar sobre as divisões, portanto, sobre a separação íntima, a autoexclusão do ser humano entre corpo e alma, animal e sobrenatural. Esta a sugestão da página de Agamben que quero recolher.

Há uma sugestão específica, no final da passagem citada: é aquela de uma urgência deste trabalho dedicado às divisões/exclusões internas ao ser humano sobre aquele de uma tomada de posição ética ou política sobre os valores políticos contemporâneos. Entre as grandes questões e valores, obviamente, in primis aqueles da democracia, hoje tão violentada. O estado 
de exceção em que se encontram- nossas democracias ocidentais, os dias excepcionais em que vivemos neste final da segunda década do terceiro milênio, nos convidam mais uma vez a voltar às archai da construção do pensamento político.

Minha proposta é aquela de fazer um trabalho agambeniano, portanto, uma espécie de arqueologia erudita do pensamento político ocidental (no sentido foucaultiano), mas irei obviamente um pouco mais atrás no tempo, pela verdade, pois Agamben é um medievalista.

De fato, a esta questão da divisão íntima do ser humano (e, por consequência, de todo seu mundo político, cultural) Platão dedicou páginas entre as mais belas e importantes de toda a história da filosofia e do pensamento ocidental mais em geral.

A esta questão foi dado o nome, na filosofia, de dualismo e Platão é frequentemente chamado em causa pela tradição filosófica por ter um papel central na difusão de uma metafísica dualista. Lembro aqui do célebre artigo de Sarah Broadie Soul and Body in Plato and Descartes, em que ela afirma que Platão e Descartes são considerados comumente como os mais eminentes dualistas da tradição ocidental". ${ }^{2}$

O projeto portanto é aquele de trabalhar - como convida Agamben sobre os músculos e os tendões desta divisão entre humano e não-humano no interior da tradição platônica.

\section{O CANTO De Sócrates}

Em Platão há páginas centrais em que a constituição rachada (dividida), bipartida (ou por vezes até tripartida), do ser humano é desenhada e debatida. No interior deste conjunto há passagens, em Platão, dedicadas mais especificamente à relação do ser humano com os animais e com sua própria animalidade.

Não pretendo aqui dar uma noção panorâmica da questão da animalidade e da humanidade em Platão. Remeto para isso para um recente artigo

2 Broadie 2001: 295. 
publicado na revista Archai por Jerôme Laurent em 2013, intitulado L'animalité de l'homme selon Platon, no interior de um dossiê dedicado ao tema Les animaux et l'éthique, que publica os proceedings de um seminário homônimo, organizado por René Lefebvre na Universidade de Rennes em 2012. Como também o mais recente Plato's Animals, editado por Bell \& Nass em 2015.

Escolho, aqui, entre tantas outras possíveis, as páginas iniciais de um diálogo que a tradição considerou um diálogo de tema ético: ethikos (assim o chamava em sua lista Diógenes Laércio (Vitae III, 58). Trata-se do Fédon ou Sobre a Alma. O titulo do texto já seria motivo suficiente para esta escolha no contexto de um projeto como este. De fato, o diálogo tem sido utilizado por toda a história do pensamento ocidental como pedra miliar para todas as formas de dualismo psicofísico.

Mas é especialmente o contexto dramático que me fez escolher estas páginas: Sócrates, personagem principal dos diálogos, encontra-se no limiar entre vida e morte, no último dia de sua vida, à espera da execução por mão das autoridades de Atenas. Está reunido com seus amigos e discípulos mais queridos e fala, como não poderia deixar de ser, sobre... bem, sobre o que vale a pena falar em momentos limiares como estes: vida, morte, paixões, felicidade. De maneira especial Sócrates (estamos aqui entrando no coração do trabalho sobre a divisão proposto por Agamben) procura provar a seus companheiros que a morte não existe e que o ser humano - ou pelo menos parte dele, sua alma - é imortal. Trata-se de mais do que uma tentativa de consolação (é isso também), o desenho é aquele de uma proposta metafísica (e ao mesmo tempo antropológica e ética) muito precisa: o dualismo da divisão, exatamente.

O propósito central do diálogo é a tentativa de Sócrates de consolar e convencer os amigos que vieram visitá-lo de que a morte é preferível à vida, pois a morte significa a liberação da alma do corpo, para uma vida imortal e feliz ao lado dos deuses. Isto é, que a morte consumará finalmente a divisão psicofísica desejada pelo filósofo ao longo da vida toda e assim percebida como libertação da alma do corpo. A passagem central é bem conhecida: 
Crês, portanto, sem restrições, que os interesses de um homem desta têmpera [o filósofo] nada têm a ver com o corpo e que, pelo contrário, a ele renuncia até onde lhe for possível, para se concentrar sobre a alma? [...]. E é ou não por indícios desses que o verdadeiro filósofo se revela logo como tal - dando o melhor de si para emancipar a alma do comércio com o corpo, e sobrelevando nisso todos os demais? [...]. Por outro lado, Símias, é preconceito corrente entre os homens, creio, que aquele que não se agrade dessas coisas vulgares, nem tome parte nelas, não merece viver: pois (pensam) que é isso de rejeitar os prazeres que o corpo proporciona, senão estar a dois passos da morte. ${ }^{3}$

Não é inútil para a economia desta nossa leitura anotar que a tentativa de Sócrates de persuadir os amigos a não chorar a morte dele teve pouco sucesso, se consideramos uma página belíssima, que a literatura etiquetou como o verdadeiro canto do cisne de Sócrates. Não acaso a página inicia com um sorriso de Sócrates:

Ao ouvi-lo Sócrates riu de leve e exclamou: Ora, ora, Símias! Vejo que será realmente difícil convencer os outros que não penso na morte como numa desgraça, quando nem sequer consigo convencer vocês disso; aliás, vocês estão receosos de que esteja de humor ainda pior do que estava durante toda minha vida. Ao que parece vocês não me consideram no mesmo nível dos cisnes na arte da adivinhação. Estes, de fato, ao pressentirem que a morte está próxima, ainda que cantassem também antes, o fazem neste momento de forma mais intensa e sumamente bela, pela alegria de estar a ponto de encontrarem o deus que servem. Os seres humanos, ao contrário, pelo medo que têm da morte, se enganam sobre os cisnes e dizem que eles, chorando a morte, elevam um canto de despedida movidos pela dor, e não se dão conta que nenhuma ave canta quando sente fome ou sede ou esteja sentindo qualquer dor, nem mesmo os rouxinóis, as andorinhas e as poupas ${ }^{4}$, das quais se diz que cantam lamentando-se pela dor. A mim parece o

3 Pl. Phd 64e-65a - Trad. Schiappa Azevedo.

4 A referência aqui é à lenda de Procne, Tereu e Filomela, que, por uma atrocidade, são transformados, respectivamente, nas três aves citadas (cf. aqui Trabattoni 2011: 129). 
contrário: que nem estas aves nem os cisnes cantam tomados pela dor, mas, por serem de Apolo, eles são adivinhos, conhecendo assim de antemão os bens que os esperam no Hades, por isso cantam de alegria, neste dia [da morte], mais do que no passado. Quanto a mim, eu me considero um companheiro de servidão dos cisnes, consagrado ao deus como esses, e creio ter recebido de nosso dono a arte da adivinhação na mesma medida, e creio me despedir da vida com uma serenidade não inferior à deles. ${ }^{5}$

É importante aqui anotar que o canto do cisne é claramente uma analogia do canto do próprio Sócrates no corredor da morte. O canto de Sócrates, portanto como o do cisne, não seria um canto de dor, e sim um canto à imortalidade da alma. Daí o sorriso de Sócrates, de leve, que abre maravilhosamente a passagem.

Não acaso o próprio Sócrates, em seus últimos dias de vida, canta (ou, melhor, compõe poesia cantada). Ao responder aos companheiros, que estavam surpreendidos com esta inédita atividade poética de Sócrates, este confessa que um sonho era recorrente em sua vida:

Muitas pessoas me perguntavam - diz Cebes - e mesmo o outro dia o próprio Eveno: o que passou pela tua cabeça, desde que estás aqui [na prisão], de compor poesia, você que jamais havia composto um verso antes disto? (...) Se portanto te importa que eu possa dar uma resposta a Eveno, da próxima vez que o encontrar, me diga por favor o que devo responder-lhe.

Diga-lhe a verdade - respondeu Sócrates. Que não foi intenção minha competir com ele ou com seus poemas - sabia que não era coisa fácil, mas estava apenas tentando compreender o sentido de alguns dos meus sonhos e cumprir um dever para com os deuses, caso fosse essa a espécie de música que me ordenava de compor. Trata-se em linhas gerais do seguinte: várias vezes, ao longo de minha vida, vinha me visitar o mesmo sonho, que me visitava com visões a cada vez diferentes, mas dizendo as mesmas coisas:

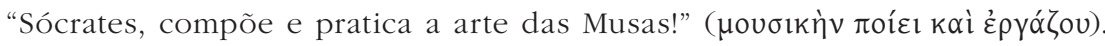
Eu, pelo menos no passado, tomava o sonho como uma exortação e um

5 Pl. Phd 84d-85b. 
estímulo para fazer exatamente o que estava fazendo, como se incitam os corredores: assim pensava que o sonho me encorajasse a praticar a arte das Musas, pois a filosofia, que estava praticando, é a forma mais alta da arte das Musas. ${ }^{6}$ Agora, todavia, que o julgamento acabou e que as festas em honra do deus impediram que eu morresse, ${ }^{7}$ me veio a dúvida se o sonho não estivesse me incitando a produzir este tipo de música, como é entendida

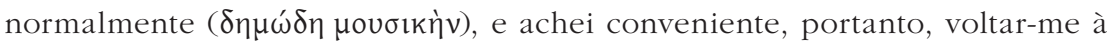
poesia, para, no caso de assim ser, não cair em desobediência. Era efetivamente mais seguro partir depois de cumprir com esta obrigação, compondo poesias em obediência ao sonho. Assim, por primeira coisa, compus para o deus em honra do qual são dedicadas as presentes festividades; depois do deus, considerando que o poeta, se quer ser realmente poeta, deve compor contos

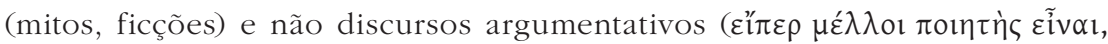

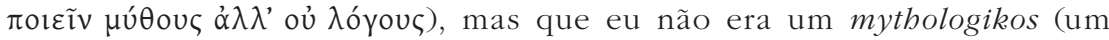
escritor de contos), por esta razão entre os contos que tinha à mão e conhecia, aqueles de Esopo, coloquei em versos os primeiros que encontrei. ${ }^{8}$

Os poemas musicados que Sócrates compõe utilizam-se das fábulas de Esopo e de um hino a Apolo (Phd. 60b). A menção às fábulas de Esopo não é casual, como veremos. Sócrates até tenta, de certa maneira, dar pouca importância às fábulas de Esopo, como a querer sugerir que por não ser um mythologikos, um escritor de contos, teria apanhado a primeira coisa que tinha à mão. Ao contrário, os comentadores revelam que a aproximação de Sócrates e Esopo neste momento da condenação à morte seria uma estratégia de Platão para, aproximando as biografias dos dois, enaltecer mais uma vez o Mestre.? Mas o que mais interessa para a economia de nosso argumento aqui é que tanto os poemas sobre as fábulas de Esopo como a bela analogia do cisne revelam uma presença surpreendente, nestas

6 Cf. P. R. VIII, 548b e Phdr. 259d

7 Trata-se aqui do festival das Délias, que acontece no monte Antestérion (Cf. Xen. Memor. 4.8.2), e portanto entre os meses de fevereiro e março.

8 Pl. Phd. 60c-61c.

9 Cf. Compton 1990 e Clayton 2008. 
horas dramáticas de Sócrates no corredor da morte, de animais. ${ }^{10} \mathrm{Na}$ verdade, Sócrates é comparado e compara-se a si mesmo constantemente a animais em seus diálogos. A obra de Platão como um todo é atravessada por animais, há um enorme bestiário frequentando estes textos: formigas, abelhas, mosquitos, cavalos, raposas, sapos, peixes, leões, lobos, cachorros, vacas e bois, rouxinois e passarinhos, ovelhas, cisnes, frangos, galos, ostras, serpentes, entre outros.

Se pense por exemplo no mesmo Fédon na página 81b-e.

As fábulas de Esopo, de fato, são bem conhecidas de todos: trata-se, em sua imensa maioria, de fábulas em que os animais representam tipos éticos e, por isso, agem de fato como seres humanos. Novamente, a economia de nosso ensaio nos obriga a prestar atenção a uma característica bastante peculiar dos animais de Esopo: eles falam. Estes diálogos ético-políticos dos animais são o que mais nos interessa. As palavras, o logos, é democracia! O uso das analogias e de uma forma de elenchos nos diálogos dos animais de Esopo novamente os aproximam enormemente a Sócrates. Creio que o círculo hermenêutico esteja agora bem estabelecido: a menção a Esopo no início do Fédon está bem longe de ser casual.11

Ecoa aqui, obviamente, a celebre definição aristotélica (presente na primeira página da Política) do ser humano como zoon logikon, isto é, como animal que fala (melhor do que animal racional, tradução à qual fomos acostumados por tanta tradição racionalista de nosso pensamento). Obviamente, os animais não falam, Aristóteles tem razão a sublinhar esta "unicidade" do ser humano.

\section{Animais Que falam E o SilÊNCiO Do SER HUMANO}

Assim o cisne que canta (sua alegria na frente da morte) e os animais falantes de Esopo estão aí, nos desafiando a uma compreensão.

10 Northwood 2015.

11 Kurke 2006. 
As duas imagens remetem para uma terceira (e última) imagem paralela a esta, contida no Político de Platão. Trata-se do mito da era de Cronos, um tempo originário e paradisíaco - se me permitem o anacronismo - em que os seres humanos, pastoreados como ovelhas pelos deuses Pastores, viviam perfeitamente felizes. A descrição desta vita beata originária inclui, como não podia ser diferente, topoi comuns a muitos destes mitos de origem: uma nudez sem pudor, a vida ao ar livre, a inexistência de dor, um clima ameno. ${ }^{12}$ Mas a descrição deste momento continua, de maneira ainda mais interessante para nossa discussão aqui, da seguinte maneira:

Os seres humanos que foram criados por Cronos, tendo muito tempo à disposição (schole, 272b8) e a capacidade de se encontrarem para conversar não somente com os homens mas também com os animais, aproveitavam

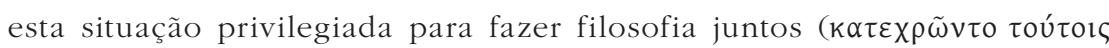

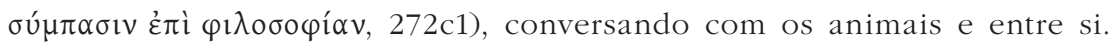
Interrogavam cada espécie para saber se alguma, possuindo uma capacidade específica, compreendia algo de superior às outras. É fácil perceber que há uma imensa diferença com relação à felicidade ( $\pi \rho$ ò $\varepsilon u ̉ \delta \alpha \iota \mu o v i ́ \alpha v, 272 c 5$ ) entre aqueles que vivem hoje e aqueles que viviam então: comendo e bebendo à vontade, conversavam entre eles e com os animais. ${ }^{13}$

O mito foi estudado exaustivamente por Vidal-Naquet (1986) e mais recentemente nos belos comentários ao Político de Melissa Lane e de Sayre.14 Nenhum deles todavia parece se interessar naquilo que nos interessa aqui especialmente: a repetição $(3 x)$ da menção ao fato que os seres humanos conversavam com os animais. ${ }^{15}$ Eis aqui portanto novamente a imagem de animais que falam. Uma menção única na obra de Platão, mas que encontra facilmente eco na tradição mais antiga, da qual as fábulas de Esopo são provavelmente resquícios literários. Animais falam nas comédias, na sátira

12 Pl. Pol. 272a.

13 Pl. Pol. 272b-c. A tradução é minha.

14 Lane 1998: 112; Sayre 2006.

15 Krell (2016, pos. 711) é o único a considerar a fala dos animais em seu comentário a passagem. A estranheza da imagem lhe faz dizer, de forma pouco ritual, que se trata de um mito whimsy, esquisito. 
e nas paródias da épica (como é o caso da Batracomiomaquia). Mas são realmente as fábulas "os verdadeiros campeões da eloquência animal". ${ }^{16}$ É especialmente significativo o comentário final da passagem: os seres humanos eram então mais felizes. Assim como os animais, provavelmente. Eram felizes pois compartilhavam entre si da sintaxe da vida. A busca pela felicidade da comunidade, da maximização da vida boa para a maioria dos cidadãos, é desde sempre promessa democrática mais importante, que se alia àquela da procura de unidade, ou da falta de divisão, como conditio sine qua non para a facilidade dos muitos. Uma promessa de felicidade, esta da vida na cidade, a tal ponto irresistível que somente uma besta ou um deus poderiam resistir a ela, dizia Aristóteles. ${ }^{17}$

Há algo essencial aqui que diz respeito à pragmática desta passagem: como as fábulas de Esopo, o mito originário de Platão é atemporal, no sentido que se põe fora do curso normal do tempo (na origem, como este é caso, ou ao final dos tempos, como é o caso da apocalítica de Agamben). Fora para poder ser deste mesmo curso a norma de referência. Neste caso, portanto, a felicidade das origens é pensada como indicação de uma felicidade latente, de uma norma ético-política de convivência entre homens e animais, no caso específico, que deveria ser hoje, isto é, no tempo presente, recuperada. A história da era Cronos, amplamente lembrada pela literatura do século IV, traz de fato imediatamente à mente o contraste com a era presente, de conflito e dissenso político que marca a democracia e sua derrota histórica ao longo do século IV.18

Obviamente, ninguém pensa seriamente que um dia destes possamos sentar e filosofar com uma formiga ou uma serpente. Nem Platão nem Esopo nem o javista do Livro de Gênesis (se me permitem), nem o autor dos mitos africanos ou ameríndios. Todos eles repletos de animais falantes.

Qual seria portanto o sentido mais profundo desta remissão ao tempo em que homens a animais viviam juntos e falavam entre eles?

16 Dumont 2011.

17 Arist. Pol.1.1253a20.

18 Lane 1998: 111-112. 
Creio que para isso seja o caso de voltar à sugestão da página de Agamben citada no início: trabalhar sobre as divisões, portanto, sobre a separação íntima, a auto-exclusão do ser humano entre corpo e alma, animal e sobrenatural.

O atual silêncio entre ser humano e animal, diferentemente do diálogo que havia no tempo de Cronos (ou no Gênesis), é a cifra de um drama íntimo do ser humano de hoje: suas partes, sobrenatural e animal, alma e corpo, já não conversam mais entre si. Com consequências que dizem respeito ao equilíbrio do ser humano e deste com a natureza (especialmente com os animais) e os outros seres humanos, como fica especialmente evidente na Queda do mito de origem da Bíblia Hebraica, por exemplo.

É a esta disgiunzione (disjunção) que Agamben nos convida a pensar.

O problema é, portanto, o reconhecimento e a operacionalização desta barreira entre o sobrenatural e o animal no ser humano (um jeito moderno de pensar o dualismo corpo-alma, obviamente). Não a negação desta barreira móvel, pretendida por tanta metafísica e política ocidental. Os animais, tão presentes em nossas narrativas originárias, são o sinal da impossibilidade, no limite, desta separação. Os animais, ontem como hoje, estão aí, nos encarando, em silêncio. Eles são o Outro, ${ }^{19}$ mas um outro que encontramos de certa forma em nossas origens e dentro de nós o tempo todo. Nos lembram de uma abertura (outro conceito agambeniano) que existe dentro do ser humano e que não pode ser fechada, apesar de todas as tentativas neste sentido de grande parte de nossa cultura: é o aberto entre homem e animal, que é uma abertura, uma falha aberta dentro do próprio humano.

O silêncio ensurdecedor que marca a condição íntima da separação revela uma tragédia anunciada: o descolamento das duas partes constitutivas do ser humano impede sua plena realização, sua felicidade plena. Mas, se seguirmos a sugestão das fábulas de Esopo e do mito dos animais falantes, o silêncio tem também, para além de um resultado ético-político trágico, uma consequência epistemológica gravíssima: impede o pleno conhecimento do mundo. Pois impede o diálogo, que é a essência da filosofia platônica e da utopia democrática. O diálogo filosófico das origens entre homens e

19 Heath 2005: 15. 
animais é assim signo da abertura necessária dentro do ser humano entre suas partes, e possibilidade de superar a dialética de exclusão/inclusão dos conceitos delimitadores das pretensas divisões metafísicas.

Me descubro várias vezes pensando se não seria esta a razão dramática e quiçá existencial pela qual Sócrates, nos últimos dias de sua vida, decide musicar fábulas de animais falantes. No liminar do termo maior desta separação entre corpo e alma, entre animal e sobrenatural, que é a morte, os animais de Esopo devem ter lhe parecido a melhor maneira de romper o silêncio dos conceitos, que lhe é imposto pela falência da política e sua condenação à morte pela democracia. Recuperando com a poesia/música um diálogo e uma abertura em boa parte perdidos. E de tocar assim a totalidade da vida, em lugar de reafirmar simplesmente a divisão. Nada melhor do que os mitos cantados desde sempre para isso: os mitos - como a fábula de Esopo - são por si mesmos abertos, janelas originárias sobre a condição humana mais íntima.

\section{Conclusão}

Ao final Platão não era lá tão dualista como fomos acostumados a pensar. Ao contrário, é alguém que sobre as divisões trabalha duro.

Platão, como Agamben, parece querer nos ensinar, especialmente em momentos dramáticos e limiares como estes, a prestar a devida atenção à dimensão ontológica dos problemas políticos. Neste caso, de maneira especial, trata-se de reconhecer a divisão íntima do ser humano e o silêncio que dela resulta. Silêncio e divisão que o ser humano, obviamente, projeta em todas suas produções culturais e políticas, incluindo nesta o histórico e dramático fracasso da democracia e da própria polis: obviamente. Este fracasso, representado dolorosamente pela morte de Sócrates, que é sempre o ponto de partida e a preocupação principal da política e da metafísica platônica. 


\section{REFERÊNCIAS}

Agamben, G. (2002), L'aperto: l'uomo e l'animale. Torino.

Aristotle. (1998), Politics (trans. Reeve, C. D. C.). Indianapolis.

Brisson, L. (ed.) (2008), Platon. OEuvres complètes. Paris.

Broadie, S. (2001), Soul and Body in Plato and Descartes. PAS 101: 295-308.

Diogenes Laertius. (2013), Lives of eminent philosophers (edited with an introduction by Tiziano Dorandi). Cambridge.

Dumont, J. (2001), Les animaux dans l'antiquitè grecque. Paris.

Heath, J. (2005), The talking Greeks: Speech, Animals, and the Other in Homer, Aeschylus, and Plato. Cambridge.

Sayre, K. M. (2006), Metaphysics and Method in Plato's Statesman. Cambridge.

Krell, D. F. (2015), "Talk to the Animals: On the Myth of Cronos in the Statesman", in Bell, J. R. \& Naas, M. B. (eds), Plato's Animals: Gadflies, Horses, Swans, and Other Philosophical Beasts. Bloomington.

Laurent, J. (2013), "L’animalité de l'homme selon Platon". Archai 11: 79-90.

Platão. (2000), Fédon (introdução, tradução e notas por Maria Teresa Nogueira Schiappa de Azevedo). Brasília.

Platone. (2011), Fedone (a cura di F. Trabattoni. Trad. S. Martinelli Tempesta). Torino.

Vidal-Naquet, P. (1986), The Black Hunter: Forms of Thought and Forms of Society in the Greek World. Cambridge.

Xenophon. (1997), Memorabilia. Oeconomicus. Symposium. Apology, (transl. of E. C. Marchantand and O. J. Todd). Cambridge. 